\title{
Combinando Frameworks no Desenvolvimento de Artefatos Digitais: Um Estudo de Viabilidade
}

Combining Frameworks in the Development of the Digital Artifacts: A Feasibility Study.

KAWAKAMI, Guto; Me; Sidia - Samsung Instituto de Desenvolvimento e Informática na Amazônia

Guto.kawakami@gmail.com

TELES, Sylker; Phd; Fucapi - Fundação Centro de Análise Pesquisa e Inovação Tecnológica

Sylker@gmail.com

\section{Resumo}

O mercado de artefatos digitais tem ganhado cada vez mais espaço devido sua proliferação através dos smartphones. Diante disso, varias metodologias vem sendo desenvolvidas para auxiliar estudantes e profissionais no desenvolvimento e na condução de projetos de software. Atualmente já existem alguns métodos disponíveis, porém, apesar do mercado utiliza-los em seu ambiente corporativo, a academia desconhece suas particularidades e boas práticas, o que acarreta na formação de estudantes fora do perfil que a indústria deseja. Neste trabalho de pesquisa é realizado um estudo de viabilidade aplicando diversas metodologias do mercado em projetos de software no meio acadêmico, com o intuito de gerar um novo framework derivado da combinação dessas abordagens, para que possa auxiliar estudantes no processo de desenvolvimento, consequentemente capacitando-os para ingressar no mercado. As abordagens utilizadas neste estudo foram: Scrum, Challenge Based Learning, Lean Startup e Design Thinking.

Palavras Chave: Scrum; Challenge Based Learning; Lean Startup; Design Thinking.

\section{Abstract}

The digital artifacts market has gained more and more space due its proliferation through smartphones. Due to this, several methodologies have been developed to help students and professionals in the development and conduction of software projects. Currently there are some methods available, however, although the market uses them in corporate environment, the academy does not know their particularities and good practices, which leads to training of students outside of the profile that industry wants. In this work, is applied a feasibility study using several market methodologies in software projects in the academic environment, with the aim of generating a new framework derived from the combination these approaches, in order to help students in the development process and prepares them to enter market. The approaches used in this study were: Scrum, Challenge Based Learning, Lean Startup and Design Thinking.

Keywords: Scrum; Challenge Based Learning; Lean Startup and Design Thinking. 


\section{Introdução}

Entende-se como um artefato digital "qualquer objeto produzido por TIC (Tecnologias de Informação e Comunicação Contemporâneas), ou seja, tanto sistemas e programas computacionais (software) e suas interfaces do usuário, quanto os objetos físicos que os abrigam" (SIGNORINI, 2010, p.4). Tendo esta definição como parâmetro, podemos citar como exemplos desses artefatos: os aplicativos, web sites, sistemas para desktop, entre outros.

O crescimento do uso dos smartphones consequente proliferou a utilização de artefatos digitais no cotidiano da sociedade, segundo Ferreira et al. $(2005$, p.2) "os aplicativos exercem na atualidade uma influência decisiva nas atividades e no desenvolvimento humano", diante disso, atividades como: pagar contas bancárias, comunicação rápida, pedido de transporte, dentre outras, podem ser citadas como tarefas que estão sendo facilitadas por meio dessas tecnologias.

A grande diferença no mercado de smartphones são as funções personalizadas dos aplicativos, o que dá liberdade para cada fabricante customizar seus serviços (Chammas et al, 2013, p148). Dito isto, um leque de oportunidades surgiu para profissionais de diversas áreas desenvolverem seus produtos, assim como, abordagens e variados frameworks foram criados para auxilia-los no processo de desenvolvimento. Dentre as abordagens estão as metodologias ágeis, os métodos para deixar um produto mais enxuto e atribuir valor de negócio, frameworks educacionais, técnicas para conhecer o usuário e etc.

No entanto, grande parte das abordagens utilizadas no processo de desenvolvimento são colocadas em prática apenas no mercado, logo, os estudantes da graduação podem enfrentar dificuldades no processo de adaptação ao ingressar no ambiente industrial, visto que muitas dessas práticas são desconhecidas. Nauman e Uzair dizem que "existe uma grande lacuna entre as técnicas ensinadas aos estudantes universitários e as praticadas pela indústria" (2007, p.19, tradução nossa). Isto acontece porque a academia tradicionalmente utiliza-se de aulas expositivas e leituras complementares para repassar fundamentos, e um curto espaço de tempo para o desenvolvimento de projetos (Huang e Distante, 2006), o que gera insatisfação na preparação dos universitários recém-formados que ingressam no mercado, pois quando adentram a indústria, encontram um cenário no qual as técnicas e métodos aprendidos na graduação são pouco aplicados (Meireles e Bonifácio, 2015). Por esta razão, torna-se importante trazer para o ambiente acadêmico abordagens utilizadas no mercado, pois irão aproximar o estudante do que o aguarda no mundo profissional, além de lapida-lo com um perfil mais desejado.

Diante do exposto, este trabalho apresenta um estudo de viabilidade que foi executado com o propósito de verificar as possibilidades de combinação das abordagens utilizadas no mercado, no intuito de obter dados para a criação de um novo framework que possa auxiliar os estudantes no desenvolvimento de artefatos digitais e consequentemente capacita-los para adentrar o mercado. Neste estudo de viabilidade foram utilizados os métodos: Scrum, MVP Minimum Viable Product, Design Thinking e Challenge Based Learning.

\section{O Estado da Arte}

Para compreender melhor as necessidades da academia e do mercado dentro do contexto de artefatos digitais, faz-se necessário uma revisão da literatura sobre as abordagens que facilitam o processo de desenvolvimento em diferentes aspectos. Este capítulo irá explanar o estado da arte das abordagens escolhidas. Dentro do contexto de Ensino/Aprendizagem foi escolhido o 
método CBL - Challenge Based Learning (O Aprendizado Baseado em Desafios) por seguir conceitos construtivistas onde o aluno é o protagonista do próprio conhecimento. Para a condução de projetos, a metodologia ágil Scrum será utilizada, uma vez que é uma das mais conhecidas no mercado. No contexto de pesquisa, o Design Thinking foi o método escolhido por fornecer um repertório de técnicas para conhecer o usuário. E por fim, no contexto de validação, a técnica do Produto Mínimo Viável (MVP) será usada pelo fato de prover um aprendizado de forma prática através do feedback do público-alvo.

\subsection{O Aprendizado Baseado em Desafios}

$O$ aprendizado baseado em desafios ( $C B L$ - Challenge Based Learning) é um framework que surgiu do projeto Apple Classrooms of Tomorrow-Today (ACOT2) iniciado em 2008 com o objetivo de identificar os princípios de design essenciais em um ambiente de aprendizagem do século XXI (Nichols et al, 2016, p.7). O método contém 3 etapas que podem ser seguidas de maneira flexível, dependendo das necessidades de aprendizado. As etapas que o framework fornece são: Engage (Empenho), Investigate (Investigação) e Act (Ação), cada etapa está relacionada tanto com uma fase do projeto quanto ao aprendizado do estudante.

A etapa de Engage faz o aprendiz escolher uma área de interesse que deseja desenvolver uma solução, pode ser qualquer tema, como: música, educação, cultura e etc. A escolha desse tema é algo importante, visto que é a área em que o estudante irá identificar um problema e propor uma futura solução. A etapa de Investigate é o momento para realizar pesquisas rigorosas dentro do contexto da área escolhida, esta pesquisa irá sustentar uma base de dados para gerar soluções sustentáveis e acionáveis. E finalmente na etapa Act, os indivíduos irão desenvolver soluções fundamentadas e receber feedback, aprendendo com seus próprios erros (Nichols et al, 2016). A figura 1 mostra um esquema das etapas do framework.

Figura 1 - Etapas do Processo CBL

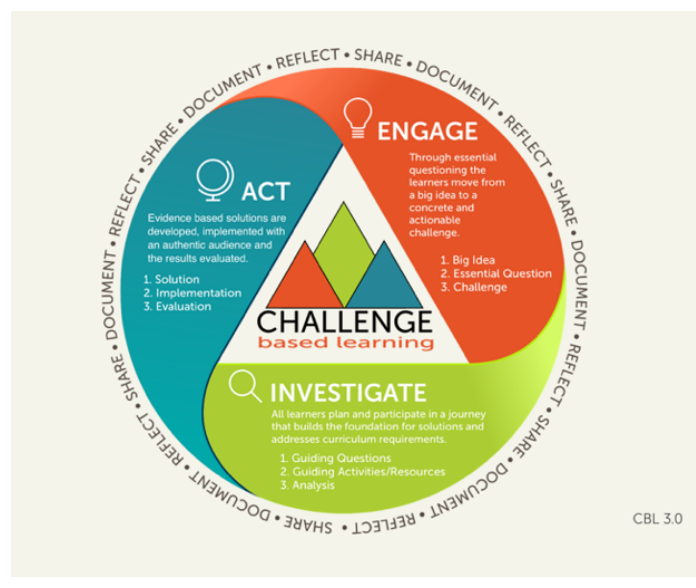

Fonte: Nichols et al, 2016.

O método CBL já foi utilizado em muitas escolas e projetos no mundo todo, dentre eles podemos citar a Apple Developer Academy. Este projeto capacita estudantes nas plataformas embarcadas da Apple: iOS (iPhone, iPad e iPod), watchOS (Apple Watch) e tvOS (Apple Tv). É 
desenvolvido em dez universidades e centros de pesquisa em todas as regiões do Brasil, ${ }^{1}$ e também com uma sede em Nápoles - Itália ${ }^{2}$. O projeto utiliza a aprendizagem baseada em desafios na criação de artefatos digitais, permitindo que os estudantes desenvolvam suas próprias soluções utilizando tecnologia de ponta em laboratórios de última geração. Como resultado deste experimento, obteve-se diversos aplicativos submetidos na AppStore, sendo alguns deles casos de sucesso a nível mundial, ganhando prêmios como Apple Design Awards ${ }^{3}$ e Apple Scholarships ${ }^{4}$. A abordagem também está presente em escolas pelo mundo, como por exemplo a Carrol Middle School em Raleigh - Carolina do Norte, Aitken Creek Primary School - Austrália, National University of Río Negro - Argentina entre outras.

Contudo, o método CBL - Challenge Based Learning é uma abordagem criada a pouco tempo, mas que vem conquistando seu espaço pelo mundo aos poucos. Além de ser apoiado pela Apple, também disponibiliza documentação de uso e realiza treinamentos periodicamente para professores de muitos países. A premissa de colocar o aluno como o protagonista na construção do aprendizado é o grande diferencial do framework e o fator incentivador para o uso deste método no estudo narrado neste artigo.

\subsection{A Metodologia Ágil Scrum}

Os métodos ágeis têm despertado um grande interesse na comunidade de desenvolvimento de software, e apesar de já existirem diversos métodos, todos tem uma coisa em comum: seguem os princípios do Manifesto Ágil. Este manifesto disponibiliza um conjunto de princípios que definem critérios para os processos de desenvolvimento de software (Fagundes, 2005). Estes valores são chamados de "valores ágeis", e todas as metodologias que utilizam o conceito de agilidade, seguem estes princípios, sendo eles:

- Indivíduos e interações mais do que processos e ferramentas.

- Software em funcionamento mais do que documentação abrangente.

- Colaboração com o cliente mais do que negociação de contratos.

- Responder a mudanças mais do que seguir um plano. ${ }^{5}$

Neste estudo, será utilizado a metodologia Ágil Scrum. No livro Scrum: Gestão Ágil para Projetos de Sucesso, Sabbagh (2014) conceitua a abordagem da seguinte forma:

\footnotetext{
"Scrum é um framework ágil, simples e leve, utilizado para a gestão do desenvolvimento de produtos complexos imersos em ambientes complexos. Scrum é embasado no empirismo, e usa uma abordagem iterativa e incremental para entregar valor com frequência, assim, reduzindo os riscos do projeto."
}

Ou seja, Scrum é um método que segue os princípios e valores do manifesto para o desenvolvimento ágil de software, pois como disse a definição é iterativo e incremental. Para descrever o funcionamento do framework, é necessário entendermos quem são os stakeholders envolvidos no método, ou seja, os atores, que são: Product Owner (P.O) - responsável pela definição do produto e maximizar o retorno para os clientes, Scrum Master - responsável em

\footnotetext{
${ }^{1}$ https://developeracademy.fucapi.br

${ }^{2}$ https://www.developeracademy.unina.it/en/

${ }^{3}$ https://developer.apple.com/design/awards/

${ }^{4}$ https://developer.apple.com/wwdc/scholarships/

${ }^{5}$ http://agilemanifesto.org/iso/ptbr/manifesto.html
} 
facilitar e potencializar o trabalho do time e o Scrum Team - grupo de pessoas responsáveis pelo desenvolvimento do produto.

Todo projeto começa com alguma ideia, objetivo ou necessidade de um cliente ou do mercado, essa necessidade é chamada de Visão do Produto. O P.O. tem o papel de definir essa visão, repassa-la ao time de desenvolvimento e priorizar o que será desenvolvido em cada ciclo. No Scrum, estes ciclos possuem tamanho fixo, acontecem de forma sequencial, sem intervalos entre eles e são chamados de Sprints. Cada Sprint tem um formato estabelecido pelos Stakeholders, sendo composto de algumas cerimônias que acontecem em momentos estratégicos, as principais cerimônias são: Sprint Planning - reunião para realizar o planejamento da Sprint, Daily Scrum - reunião diária para gerar visibilidade das tarefas do time, Sprint Review - reunião onde se obtém o feedback dos clientes em relação aos trabalhos desenvolvidos e Sprint Retrospective - momento de avaliação do formato de trabalho do time. A figura 3 apresenta o ciclo do Scrum de forma simples.

Figura 2 - O ciclo do Scrum

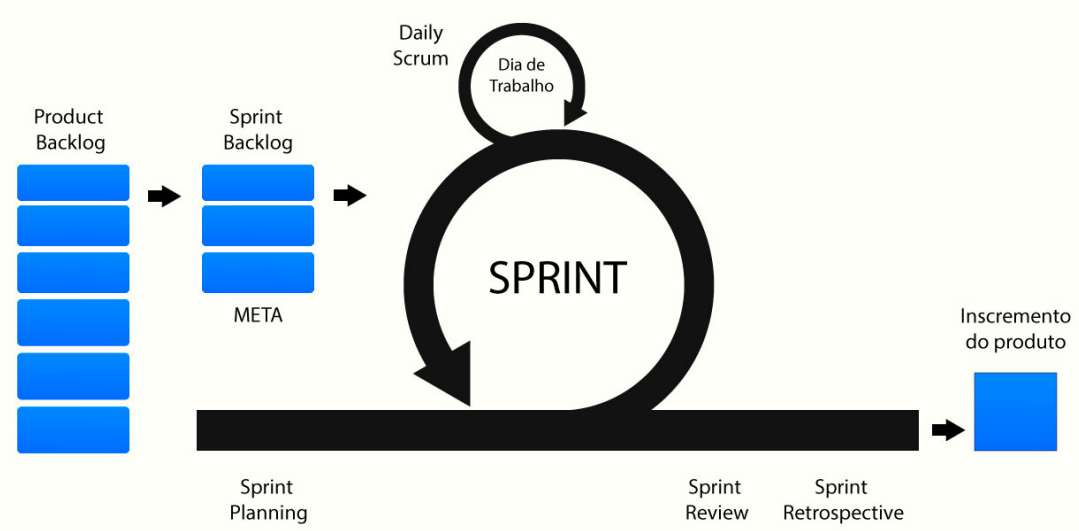

Fonte: $\mathrm{O}$ autor.

Concluindo o Sprint, é gerado um valor a ser entregue para o cliente, que pode ser um protótipo, um executável e etc. Sendo assim no final de cada Sprint o método permite que o cliente tenha algo palpável em mãos.

Em um artigo onde foi combinado os métodos Scrum e CBL, Santos et al. (2015) descreve a mistura das abordagens aplicada no desenvolvimento de artefatos digitais. De acordo com os resultados das percepções dos alunos, "foi possível descobrir que em um ambiente de ensino e aprendizagem com base na experiência prática, combinado com a abordagem baseada em desafios e o método ágil Scrum foi um modelo efetivo para os estudantes aprenderem em um curto espaço de tempo" (Santos et al., 2015, tradução nossa). Isso se faz um fator motivador para a combinação de metodologias ágeis e abordagens de aprendizado, visto que pouco ainda se sabe sobre o comportamento dos métodos quando aplicados em conjunto. 


\subsection{Design Thinking}

Devido a grande concorrência no mercado em um cenário global, inovar se tornou uma tarefa árdua, pois as dificuldades para conseguir diferenciação entre os concorrentes cresce cada vez mais na área tecnológica. Foi tentando suprir esta lacuna que se criou o que hoje é conhecido como Design Thinking. Em seu livro Design Thinking: inovação em negócios, Vianna (2012) conceitua o método como uma abordagem que utiliza um tipo de raciocínio não convencional no meio empresarial, ou seja, o pensamento abdutivo, com o objetivo de formular questionamentos através da apreensão ou compreensão dos fenômenos. A abordagem acredita que respondendo estes questionamentos de maneira abdutiva, é possível gerar uma solução que não foi derivada do problema, mas que pode ser encaixada nele.

Hoje em dia existem vários modelos de Design Thinking, De Souza et al. (2017) em seu artigo onde o mesmo realiza um mapeamento sistemático sobre modelos de Design Thinking na engenharia de software, identificou 11 modelos diferentes na literatura, sendo que alguns deles são associados a outras tecnologias ou processos de desenvolvimento, como metodologia ágil e Lean Startup. Dentre esses modelos, Paula e Cormican (2016) afirmam que o mais conhecido é o modelo proposto por Brown.

Apesar de existirem muitos modelos, todos tem um mesmo objetivo: auxiliar no alcance da inovação. A seguir será descrito um modelo definido por Vianna (2012) que divide o processo em 3 etapas: Imersão, Ideação e Prototipação, como mostra a figura 3:

Figura 3 - Etapas do processo de Design Thinking

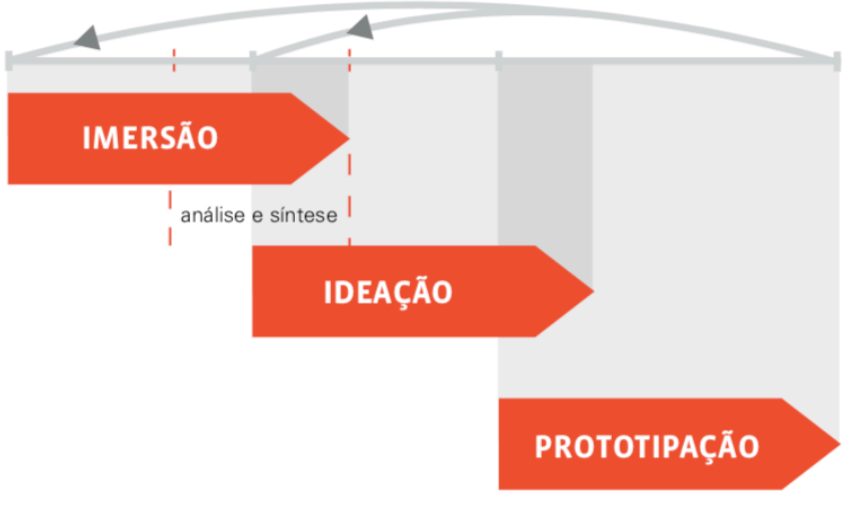

Fonte: Vianna, 2012.

Para munir os profissionais nas atividades realizadas dentro processo, a abordagem disponibiliza um repertório de técnicas que podem ser aplicadas em etapas específicas. Dentre as técnicas, estão algumas mais conhecidas como: brainstorm, sombra, personas e etc. Nas últimas duas décadas, o Design Thinking amadureceu consideravelmente ganhando popularidade em vários campos, e é considerado um paradigma novo que lida com problemas em várias áreas como tecnologia da informação, educação, negócios e medicina (Dorst, 2010, tradução nossa).

O fato do método disponibilizar um repertório de técnicas para conhecer os usuários e seus problemas faz do Design Thinking uma abordagem determinante para alcançar a inovação dentro de projetos de artefatos digitais, pois munir os estudantes destas técnicas pode facilitar o 
processo de pesquisa, e aplicado juntamente à abordagem CBL pode trazer bons resultados de ensino e aprendizado. Além do mais, no estudo sobre o estado da arte do Design Thinking, identificou-se que a metodologia já foi combinada com outros frameworks em projetos de desenvolvimento de software. Ximenes et al. (2015) em seu artigo, narra o experimento de combinar Design Thinking com métodos ágeis e Lean Startup em um projeto de artefato digital, o experimento realizado teve duração de 2 meses e o resultado mostrou que mesmo o aplicativo sendo desenvolvido por estudantes inexperientes, a validação qualitativa mostrou alta aceitação pela equipe de teste e reuniu observações positivas, o que demonstra que a abordagem pode ser combinada com outras metodologias.

\subsection{O Produto Mínimo Viável}

O mercado de artefatos digitais é um dos mercados que se expandiu e abriu oportunidades para o surgimento de pequenas empresas, porém comercializar um novo produto ou serviço é uma tarefa complexa com um resultado incerto. Depois de vivenciar várias experiências ruins, Ries (2011) criou uma nova abordagem para gerar inovação contínua, que foi denominada de Lean Startup (Startup Enxuta).

A abordagem Startup Enxuta entende que desenvolver um produto completo antes de testa-lo é uma proposta arriscada devido a extrema incerteza associada às operações de inicialização (Moogk, 2012), neste cenário, o método acredita que testar o produto no mercado em um tempo mais rápido sem que ele esteja desenvolvido por completo, pode prover um feedback em tempo hábil a equipe de desenvolvimento.

Desta forma, para uma inicialização, é essencial validar o valor e as hipóteses de crescimento do produto o mais rápido possível, logo é necessário criar um MVP - Minimum Viable Product (Produto Mínimo Viável). Segundo Moogk (2012) o MVP é uma versão do produto que seja completa o suficiente para demonstrar o valor que ele traz para os usuários. Essa técnica é uma peça-chave para atender a um dos princípios da abordagem Lean Startup que é o ciclo construir-medir-aprender (Caroli, 2015), como mostra a figura 4.

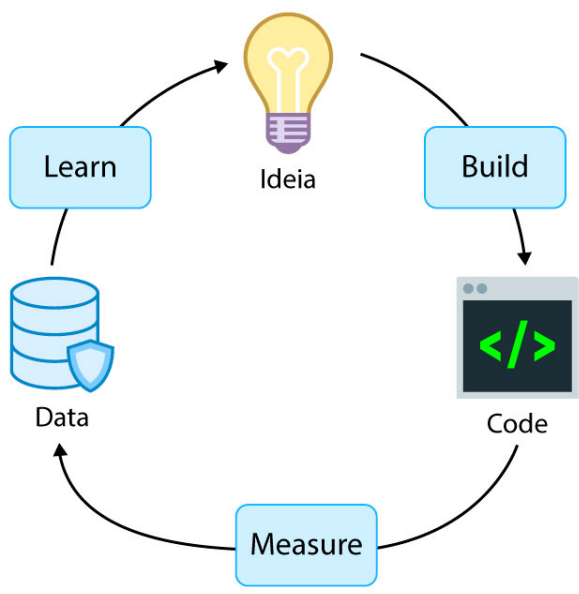


Dito isto, é possível fazer uma alusão aos métodos ágeis, pois estes também trabalham com entregas contínuas, o que já pode fazer sentido pensar em uma combinação. Além disso, a técnica também já vou utilizada junto com a abordagem de Design Thinking. Caroli (2015) em seu livro descreve a construção de um MVP a partir de técnicas de Design Thinking, como: personas, mapas de empatia e jornada do usuário. Visto que o MVP é um produto o suficiente completo para demonstrar seu valor, faz sentido utilizar o repertório de técnicas de Design Thinking para conhecer o usuário e consequentemente aplicar esses conhecimentos na construção de um produto mínimo viável.

\section{O Estudo de Viabilidade}

Segundo Shull et al. (2001), o primeiro estudo que deve ser executado ao avaliar uma nova tecnologia é um estudo de viabilidade. Neste capítulo, será descrito um estudo que responde ao seguinte questionamento: "É viável combinar frameworks distintos no desenvolvimento de artefatos digitais?". Para responder essa questão, foi feito um experimento onde alunos da graduação utilizaram vários frameworks no desenvolvimento de projetos reais de software. Cada framework tinha seu contexto específico para ser utilizado, dando liberdade aos estudantes escolherem o momento mais adequado. Desta forma, seria possível identificar se várias abordagens podem se misturar proporcionando resultados positivos no processo de desenvolvimento.

\subsection{Objetivo}

Este estudo tem como objetivo avaliar a viabilidade de uso de alguns frameworks quando aplicados em conjunto no desenvolvimento de projetos de artefatos digitais, com o propósito de identificar como eles podem se relacionar e gerar bons resultados. Para a avaliação, foi realizada uma analise sobre a opinião dos participantes sobre a facilidade de uso após a experiência dos procedimentos adotados.

\subsection{Participantes}

O estudo teve início em março de 2016 com término em outubro do mesmo ano. Ele foi conduzido na Apple Developer Academy, que está situada dentro da Faculdade Fucapi em Manaus - Am. No total, 27 alunos de graduação participaram do estudo, sendo eles de diversos cursos como: Design, Ciência da Computação, Engenharia da Computação e Sistemas de Informação. Todos os participantes foram avisados sobre este estudo e estavam de acordo em colaborar com o mesmo.

Dentre os 27 alunos participantes, 7 eram estudantes de Design que serão chamados de Designers, e 20 dos cursos de informática, que serão chamados de Desenvolvedores. Antes do estudo começar, os estudantes responderam um questionário. Este questionário tinha como objetivo detectar a experiência e o conhecimento de cada um em relação aos frameworks que serão utilizados, para obter esses dados, foram realizadas perguntas com respostas fechadas, sendo elas: (Não conheço) o participante nunca ouviu falar da técnica, (Baixa experiência) o participante conhece a técnica de forma superficial, (Média Experiência) o participante conhece a técnica e já utilizou em projetos profissionais/acadêmicos e (Alta Experiência) o participante já utiliza a técnica há mais de 2 anos e tem experiência do seu uso no mercado. Os resultados do questionário estão expressos na tabela 1. 
Tabela 1 - Experiência dos participantes

\begin{tabular}{|c|c|c|c|c|}
\hline Framework & Não conheço & Baixa experiência & Média experiência & Alta experiência \\
\hline CBL & 27 & 0 & 0 & 0 \\
\hline Scrum & 12 & 12 & 3 & 0 \\
\hline Design Thinking & 10 & 10 & 7 & 0 \\
\hline MVP & 14 & 13 & 0 & 0 \\
\hline
\end{tabular}

Fonte: $\mathrm{O}$ autor.

Através da tabela 1 foi possível identificar a experiência da turma de modo geral, neste cenário, é possível perceber que nenhum dos participantes tem alta experiência com os frameworks. Desta forma, este experimento terá uma turma de estudantes com experiências niveladas, visto que todos terão treinamentos específicos para o uso dos métodos.

Para que os projetos ganhassem equipes multidisciplinares, os 27 participantes foram distribuídos em 7 equipes, sendo 6 equipes com 4 integrantes e uma equipe de 3 integrantes. Todas as equipes eram compostas de no mínimo um designer, e o restante dos membros desenvolvedores. Essa alocação estratégica foi realizada pelos próprios participantes, com o objetivo de assegurar membros com habilidades distintas para enriquecer o resultado do produto a ser desenvolvido.

Além dos participantes que atuaram como desenvolvedores e designers, também houveram outros envolvidos neste estudo de viabilidade, como: os instrutores do projeto Apple Developer Academy, ministrantes de treinamentos, e o moderador do experimento. Os instrutores do projeto coordenaram todo o estudo de viabilidade e ministraram algumas aulas sobre determinados assuntos de desenvolvimento e design, os ministrantes lecionaram treinamentos sobre frameworks e técnicas e o moderador foi o responsável por planejar e coletar os dados durante o estudo.

\subsection{Materiais}

Para a realização deste estudo, cada membro recebeu equipamentos adequados de desenvolvimento, como: laptops, smatphones e tablets. Os participantes também puderam usufruir de um laboratório equipado com as tecnologias necessárias para auxiliar os instrutores no processo de ensino, proporcionando um ambiente ideal de aprendizagem para o século XXI.

Visto que os participantes tinham que se locomover de suas casas para o laboratório, o projeto Apple Developer Academy (ADA) também proporcionou uma bolsa de estudos para cobrir os demais gastos, neste sentido, os estudantes foram contratados como bolsistas e participaram de atividades com a carga horária de 20 horas semanais, no horário de $14 \mathrm{~h}$ às $18 \mathrm{~h}$. Dentro deste período várias atividades foram realizadas entre professores, alunos e ministrantes de treinamentos, com o intuito de fazer com que os participantes tornassem-se pessoas com visão empreendedora e capacitadas a desenvolver artefatos digitais.

\subsection{Procedimento e Coleta de Dados}

Este estudo de viabilidade foi dividido em 4 etapas, onde cada etapa teve duração de aproximadamente 2 meses, a seguir será detalhado os principais acontecimentos de cada etapa:

Etapa 1: Na primeira etapa foi realizada as cerimônias de apresentação, distribuição de equipamentos e integração com o ambiente. Os instrutores ministraram aulas sobre assuntos 
relacionados a desenvolvimento e design. Dentre os assuntos, os estudantes foram apresentados para a metodologia Design Thinking através de um workshop.

No final de todas as etapas, os instrutores desafiam os estudantes de alguma forma, o desafio desta primeira etapa foi: "Faça o melhor aplicativo que puder em uma semana". Neste desafio, os estudantes se dividiram em equipes da forma que foi explicado na seção 3.2 com o objetivo de desenvolver o melhor aplicativo. Nesta fase, os estudantes tiveram a liberdade de fazer o que pensaram ser melhor para atingir os objetivos. Após o tempo dado, as equipes realizaram apresentações mostrando os resultados atingidos. Os professores foram os avaliadores das apresentações e forneceram feedbacks sobre os erros e acertos dos estudantes. No fim, cada aluno elaborou um vídeo, onde neste vídeo havia uma reflexão pessoal sobre o que foi aprendido naquele desafio.

Etapa 2: Na segunda etapa, os instrutores continuaram ministrando aulas sobre assuntos técnicos de desenvolvimento e design. Desta vez os estudantes foram apresentados ao método ágil Scrum. A metodologia foi explicada através de um workshop e de uma atividade prática onde os estudantes deveriam utilizar a metodologia para construir cidades com lego, em cada Sprint deveria ser entregue uma parte da cidade. Este rápido treinamento serviu para entender os conceitos do Scrum, para que posteriormente os participantes pudessem aplica-los no próximo desafio, desafio este que foi: "Faça um jogo que ensine alguém a fazer algo". Este desafio teve duração de 3 semanas, onde cada Sprint tinha duração de uma semana. Ao final, os alunos apresentaram os resultados e os professores deram seu feedback como na etapa anterior, após as apresentações os alunos desenvolveram textos de reflexão falando dos aspectos que a metodologia ágil foi capaz de auxilia-los na condução do projeto.

Etapa 3: Na terceira etapa, as aulas mantiveram-se constantes, agora com assuntos mais aprofundados sobre desenvolvimento e design voltados para a plataforma iOS. Nesta etapa foi realizado 2 workshops para repassar aos alunos as definições da abordagem baseada em desafios (CBL). Os workshops foram ministrados por especialistas treinados pelo próprio criador do Framework: Nichols et al. (2016). A metodologia além de possuir uma filosofia construtivista de ensino/aprendizagem, também disponibiliza um processo para a construção de projetos, esse processo foi o foco dos workshops. Realizado o treinamento, os alunos puderam por em prática tudo o que aprenderam através do desafio lançado pelos instrutores: "Faça um aplicativo para ajudar alguém". Neste momento, os estudantes já tinham experiência utilizando Design Thinking, Scrum e agora poderiam testar o CBL. O desafio teve duração de um mês, com sprints de duas semanas. Após o término do prazo, os estudantes apresentaram os resultados para os professores e para uma equipe de especialistas em apps de São Paulo e Cupertino - Califórnia, o que gerou uma série de feedbacks. Ao término das apresentações e considerações os estudantes prepararam vídeos de reflexão, respondendo quais as vantagens e desvantagens de utilizar o método CBL no desenvolvimento de software.

Etapa 4: Na última etapa, os próprios alunos realizaram workshops individuais sobre determinados assuntos de desenvolvimento e design, desta forma, todos puderam aprender juntos, tanto instrutores quanto alunos. Após os workshops, todos os participantes do projeto participaram de um treinamento sobre MVP - Minimum Viable Product, o treinamento foi ministrado por um profissional contratado e durou dois dias, com carga horária de 8 horas, sendo 4 horas por dia. Neste treinamento foi possível que todos aprendessem os conceitos e as boas práticas no uso do método. Posteriormente, os instrutores lançaram o seguinte desafio: "Faça um 
aplicativo rentável". No momento atual, os estudantes já tinham praticado o Design Thinking, Scrum e CBL, colocando agora o MVP para ser aplicado junto com as demais abordagens. $O$ desafio teve duração de 1 mês, com sprints de duas semanas. No final todos os resultados foram apresentados aos instrutores, que forneceram feedback aos alunos. Por fim, todos os estudantes elaboraram um vídeo fazendo uma autoavaliação e relatando em quais aspectos os frameworks puderam ser úteis.

As etapas explicadas que compõem o procedimento deste estudo de viabilidade estão ilustradas na figura 5, que apresenta um roadmap deste estudo:

Figura 5-Roadmap do estudo de viabilidade

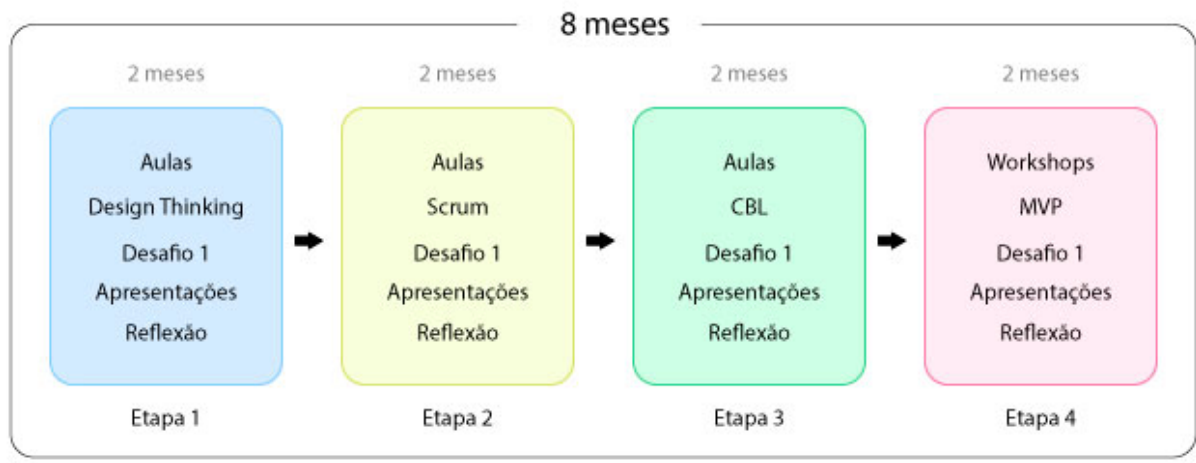

Fonte: $\mathrm{O}$ autor.

Ao término de cada etapa, os instrutores e o moderador organizaram as reflexões dos alunos em pastas para assistir suas opiniões. Após assistir, o moderador se reuniu com os instrutores para discutir questões como: como foi o processo de desenvolvimento, o trabalho em equipe e como os frameworks estão auxiliando os estudantes. Essas discussões possibilitaram captar insights de pontos negativos e positivos nos contextos aplicados, estes pontos foram adaptados periodicamente pelo moderador conforme as observações.

Por fim, o moderador realizou entrevistas com os alunos para identificar a opinião dos mesmos sobre os frameworks utilizados e como estes métodos puderam ajuda-los no desenvolvimento dos projetos. Contudo, após todos esses procedimentos foi possível obter três tipos de informações: (a) 25 entrevistas, (b) 104 reflexões e (c) dados da discussão dos instrutores, estes dados serão a base para a elaboração de uma analise qualitativa discutida no próximo capítulo.

\section{Análise dos Resultados}

A análise dos resultados começou pela avaliação das respostas contidas nas entrevistas. As entrevistas foram realizadas pelo moderador, onde o mesmo entrevistou os participantes individualmente, anotando suas respostas. Na entrevista, foi solicitado que os participantes respondessem as seguintes perguntas:

- (Q1) Antes de entrar no Apple Developer Academy você utilizou alguma metodologia para desenvolver artefatos digitais? Quais? 
- (Q2) Você acha que o processo CBL, junto com Design Thinking, MVP e Scrum o auxiliam no desenvolvimento de artefatos digitais? Por que?

- (Q3) Fazendo uma comparação entre as metodologias utilizadas no Apple Developer Academy e os métodos tradicionais, quais desvantagens/vantagens você destaca que fazem a diferença durante o processo de desenvolvimento?

Os resultados para a pergunta Q1 mostraram que a maioria dos participantes não chegaram a utilizar nenhuma metodologia para o desenvolvimento, exceto os 7 designers que já tinham experiência com Design Thinking, 3 desenvolvedores que já haviam utilizado Scrum, e outros 2 desenvolvedores relataram ter tido uma breve experiência com o método Cascata. Dois pontos interessantes são: que nenhum aluno tinha conhecimento sobre a abordagem baseada em desafios (CBL), e 13 alunos já tinham ouvido falar sobre MVP, mas nunca tinham colocado a técnica em prática.

As respostas para a pergunta Q2 indicaram que todos os participantes concordaram que a utilização dos métodos em conjunto os auxiliaram bastante no processo de desenvolvimento, a opinião do Participante 1 resume esse consenso.

"São métodos cansativos, mas estabelecem um bom resultado. O CBL mostrou a necessidade das pessoas e não a minha necessidade, o MVP encurtou o período de tempo do projeto, enxugou o máximo o projeto para chegar ao cliente o mais rápido possível. $O$ scrum ajudou na organização do time e no trabalho em equipe. O Design Thinking ajudou a entender $o$ cliente". - Participante 1.

Com respeito a pergunta Q3, foi identificado a opinião dos participantes quanto as vantagens e desvantagens do uso dos métodos, nas respostas foi possível obter feedback sobre a qualidade de uso, e também foi possível perceber que as opiniões estavam divididas, alguns acharam o método eficiente, porém cansativo, já alguns outros gostaram de utilizar a abordagem destacando apenas que requer muita disciplina dos próprios utilizadores.

Essas opiniões foram relacionadas com as reflexões elaboradas em cada etapa, neste processo os instrutores e o moderador puderam entender quais aspectos levaram os participantes a embasarem suas respostas. Entender os motivos dos participantes foi importante para a reunião de consolidação de dados, que aconteceu após a coleta e analise dos dados. A reunião foi coordenada pelo moderador com participação dos instrutores. Essa reunião tinha o objetivo de identificar as principais desvantagens no uso em conjunto dos métodos, neste caso foi analisado as opiniões dos participantes juntamente com as reflexões, e foram listados os principais defeitos sobre o uso dos métodos no processo de desenvolvimento e possíveis soluções. Na tabela 2 são listados os defeitos detectados, e uma solução discutida pelos instrutores e o moderador na reunião.

Tabela 2 - Defeitos encontrados através do estudo de viabilidade

\begin{tabular}{|l|l|}
\hline \multicolumn{1}{|c|}{ Defeito } & \multicolumn{1}{|c|}{ Solução } \\
\hline O método CBL é cansativo e demorado. & $\begin{array}{l}\text { Estudar as etapas para elaborar um rearranjo ou uma } \\
\text { forma de enxugar o método. }\end{array}$ \\
\hline $\begin{array}{l}\text { O Scrum é um método arriscado, pois se não for } \\
\text { seguido corretamente pode não atender as } \\
\text { expectativas com relação a tempo e organização. }\end{array}$ & $\begin{array}{l}\text { A primeira Sprint pode ser algo voltado à aprendizagem } \\
\text { mesclado a entregas, com o objetivo de entender o nível } \\
\text { de performance do time e o uso da metodologia ágil. }\end{array}$ \\
\hline
\end{tabular}


O Design Thinking é uma abordagem flexível, podendo ser usada a qualquer momento, porém essa liberdade pode fazer de seu uso esquecido ou usado superficialmente.

Existe uma forte relação entre o backlog e o MVP, porém ela não é estabelecida. Isso gerou dificuldades no entendimento de uso.
Estabelecer momentos estratégicos para o uso da técnica.

Estabelecer uma relação formal entre MVP e o Backlog, de forma a facilitar o uso dos frameworks em conjunto.

Fonte: $\mathrm{O}$ autor.

Os dados gerados na reunião com base nos achados (a), (b) e (c) irão contribuir para a criação de um novo modelo arquitetural de um framework para auxiliar estudantes e profissionais no desenvolvimento de artefatos digitais. Estes dados, gerados de um estudo de viabilidade visam fornecer informações para a melhoria do uso conjunto dos métodos, logo, os achados neste estudo são de suma importância para a construção desse framework.

\section{Ameaças à Validade}

Foram consideradas 3 ameaças à validade: (a) o tempo de desenvolvimento dado para cada desafio, (b) o número de participantes envolvidos no estudo e (c) se os critérios para medir a viabilidade da combinação de frameworks foram escolhidos corretamente.

Com relação à primeira ameaça, era de conhecimento do moderador e dos instrutores que o tempo que seria dado aos estudantes não seria o tempo ideal para o desenvolvimento de um projeto de artefato digital completo, logo a intenção do prazo apertado era para fins de aprendizagem das abordagens e não para o resultado do produto em si. Porém ao término do prazo, os participantes poderiam continuar os projetos nos tempos livres, o que rendeu 8 aplicativos finalizados e disponibilizados na loja para download.

O maior problema deste estudo está no tamanho da amostra. Como só houveram 27 estudantes que participaram do estudo de viabilidade, os dados extraídos devem ser considerados indicativos e não conclusivos. E finalmente, quanto a última ameaça, a satisfação e facilidade de uso percebida são critérios comuns para a investigação da produtividade de novas tecnologias (Tanaka et al., 2011). Consequentemente, a ameaça (c) não pode ser considerada um risco para a validade dos resultados obtidos.

\section{Considerações Finais}

O estudo de viabilidade apresentado neste artigo tem por objetivo verificar se é viável combinar frameworks distintos no desenvolvimento de artefatos digitais. Com o intuito de viabilizar a criação de um modelo arquitetural de um novo framework para o desenvolvimento de artefatos digitais derivados da combinação desses métodos. Este modelo a ser proposto é um trabalho futuro que foi viabilizado pelo estudo realizado neste trabalho de pesquisa.

Através dos resultados, foi possível detectar a opinião dos participantes em relação a combinação das metodologias e avalia-las. Os dados qualitativos ofereceram indícios de viabilidade da combinação desses frameworks, porém também forneceram sugestões de melhoria para uma próxima aplicação. Também foi identificado que alguns estudantes tiveram dificuldades no uso de algumas abordagens e que o processo CBL pode ser cansativo e demorado, porém todos concordaram que seu uso contribuiu para a geração de resultados positivos. O Scrum quando associado ao MVP pode gerar desentendimento, pois o backlog está associado diretamente ao 
que será entregue, logo deve haver uma relação entre ambos. E por fim a utilização do Design Thinking pareceu ter ficado facultativa, visto que é uma abordagem que pode ser aplicada em qualquer momento do processo, logo, estabelecer momentos estratégicos para a utilização da abordagem se faz necessário.

Contudo, este estudo de viabilidade buscou permitir a criação de um novo framework através da combinação de metodologias já existentes, para que este possa auxiliar estudantes no desenvolvimento de artefatos digitais e em paralelo a isso capacita-los com um perfil adequado para ingressar no mercado.

\section{Referências}

SIGNORINI, Inês et al. Língua, linguagem e mediação tecnológica. Trabalhos em Linguística Aplicada, 2010.

FERREIRA, Luis de França Gonçalves; RANGEL, Ana Cristina Souza; BERCHT, Magda. A educação matemática e a construção do numero pela criança, mediada pela tecnologia digital. RENOTE: revista novas tecnologias na educação [recurso eletrônico]. Porto Alegre, RS, 2005.

CHAMMAS, Adriana; QUARESMA, Manuela; MONT'ALVÃO, Cláudia. Um enfoque ergonômico sobre a metodologia de design de interfaces digitais para dispositivos móveis. Arcos Design, v. 7, n. 2, p. 145-171, 2013.

NAUMAN, Mohammad; UZAIR, Muhammad. SE and CS collaboration: Training students for engineering large, complex systems. In: Software Engineering Education \& Training, 2007. CSEET'07. 20th Conference on. IEEE, 2007. p. 167-174.

HUANG, Shihong; DISTANTE, Damiano. On Practice-Oriented Software Engineering Education. In: Software Engineering Education and Training Workshops, 2006. CSEETW'06. 19th Conference on. IEEE, 2006. p. 15-15.

MEIRELES, Maria Costa; BONIFÁCIO, Bruno. Uso de métodos ágeis e aprendizagem baseada em problema no ensino de engenharia de software: Um relato de experiência. In: Brazilian Symposium on Computers in Education (Simpósio Brasileiro de Informática na Educação-SBIE). 2015. p. 180.

Nichols, M., Cator, K., Torres, M. and Henderson, D. (2016) Challenge Based Learner User Guide. Redwood City, CA: Digital Promise.

SABBAGH, Rafael. Scrum: Gestão ágil para projetos de sucesso. Editora Casa do Código, 2014.

FAGUNDES, Priscila Basto et al. Framework para comparação e análise de métodos ágeis. 2005.

SANTOS, Alan R. et al. Combining challenge-based learning and scrum framework for mobile application development. In: Proceedings of the 2015 ACM Conference on Innovation and Technology in Computer Science Education. ACM, 2015. p. 189-194.

VIANNA, Maurício. Design Thinking: inovação em negócios. Design Thinking, 2012.

DE SOUZA, Anderson Felipe Barros; FERREIRA, Bruna Moraes; CONTE, Tayana. Aplicando Design Thinking em Engenharia de Software: Um Mapeamento Sistemático. 2017.

PAULA, D.; CORMICAN, K. Understanding Design Thinking in Design Studies (2006-2015): A Systematic Mapping Study. In: DS 84: Proceedings of the DESIGN 2016 14th International Design 
Conference. 2016.

DORST, Kees. The nature of design thinking. In: Design thinking research symposium. DAB Documents, 2010.

XIMENES, Bianca H.; ALVES, Isadora N.; ARAÚJO, Cristiano C. Software Project Management Combining Agile, Lean Startup and Design Thinking. In: International Conference of Design, User Experience, and Usability. Springer, Cham, 2015. p. 356-367.

RIES, Eric. The lean startup: How today's entrepreneurs use continuous innovation to create radically successful businesses. Crown Books, 2011.

MOOGK, Dobrila Rancic. Minimum viable product and the importance of experimentation in technology startups. Technology Innovation Management Review, v. 2, n. 3, p. 23, 2012.

SHULL, Forrest; CARVER, Jeffrey; TRAVASSOS, Guilherme H. An empirical methodology for introducing software processes. In: ACM SIGSOFT Software Engineering Notes. ACM, 2001. p. 288-296.

TANAKA, Eduardo Hideki; DA ROCHA, Heloísa Vieira. Evaluation of web accessibility tools. In: Proceedings of the 10th Brazilian Symposium on Human Factors in Computing Systems and the 5th Latin American Conference on Human-Computer Interaction. Brazilian Computer Society, 2011. p. 272-279. 